\title{
GIS-BASED MULTI-CRITERIA DECISION ANALYSIS FOR FOREST FIRE RISK MAPPING
}

\author{
A. E. Akay ${ }^{1 *}$, A. Erdoğan ${ }^{1}$ \\ ${ }^{1}$ Forest Engineering Department, Faculty of Forestry, Bursa Technical University, 16310 Yıldırım Bursa, Turkey - (abdullah.akay, \\ abdullah.erdogan)@btu.edu.tr
}

KEY WORDS: Forest fire risk, Multi-criteria decision, GIS, AHP

\begin{abstract}
:
The forested areas along the coastal zone of the Mediterranean region in Turkey are classified as first-degree fire sensitive areas. Forest fires are major environmental disaster that affects the sustainability of forest ecosystems. Besides, forest fires result in important economic losses and even threaten human lives. Thus, it is critical to determine the forested areas with fire risks and thereby minimize the damages on forest resources by taking necessary precaution measures in these areas. The risk of forest fire can be assessed based on various factors such as forest vegetation structures (tree species, crown closure, tree stage), topographic features (slope and aspect), and climatic parameters (temperature, wind). In this study, GIS-based Multi-Criteria Decision Analysis (MCDA) method was used to generate forest fire risk map. The study was implemented in the forested areas within Yayla Forest Enterprise Chiefs at Dursunbey Forest Enterprise Directorate which is classified as first degree fire sensitive area. In the solution process, "extAhp 2.0" plug-in running Analytic Hierarchy Process (AHP) method in ArcGIS 10.4.1 was used to categorize study area under five fire risk classes: extreme risk, high risk, moderate risk, and low risk,. The results indicated that $23.81 \%$ of the area was of extreme risk, while $25.81 \%$ was of high risk. The result indicated that the most effective criterion was tree species, followed by tree stages. The aspect had the least effective criterion on forest fire risk. It was revealed that GIS techniques integrated with MCDA methods are effective tools to quickly estimate forest fire risk at low cost. The integration of these factors into GIS can be very useful to determine forested areas with high fire risk and also to plan forestry management after fire.
\end{abstract}

\section{INTRODUCTION}

Forest fires seriously affect sustainability of forest resources especially in the dry regions covered with fire sensitive tree species (Demir et al. 2009). The coastline of Turkey from the eastern Mediterranean region to the Marmara Region, about 5.5 million hectares of forest lands are classified as first-degree fire sensitive areas (Akay et al., 2017). The average of 10,000-14,000 ha forests are burned annually as a result of over 2,000 forest fires occurred in Turkey (Sağlam et al., 2008).

Forest fires can cause serious damages on forest ecosystem that negatively affects sustainability of forest resources (Bilici, 2009). Forest fires reduce the economic value of trees and even cause loss of human lives. Besides, forest fires produce great amount of greenhouse gasses (CO2 and CH4) (Guido et al., 2004). After fire incidents, fire-damaged trees become more vulnerable to insects and fungus (Akay et al., 2007).

Forest fire risk mainly depends on various factors such as forest vegetation structures, topographic features, and climatic parameters (Carmel et al., 2009). Forest vegetation structures such as tree species, crown closure, and tree stage are separate factors that influences forest fire ignition and fire severity (Gao et al., 2011). The fire risk increases as the proportion of coniferous trees increases in a forest stand, while deciduous trees can increase fire resistance (Gazzard, 2012). Crown closure is another factor that has a positive relationship with forest fire risk (Bilgili, 2003). The fire risk is relatively low at early stages of trees, while risk is very high at young generations (Sağlam et al., 2008). Then, fire risk decreases from the mature to over mature stages, since accumulation of crown and surface fuels increases with stand age (Bilgili, 2003).
Topography is an important factor that affects the fire risk of the area (Erten et al., 2004). Fire potentially moves least rapidly down slopes and most rapidly up slopes. Besides, the fire risk increases as ground slope increases (Jaiswal et al., 2002). In term of aspect, fire risk is higher in south-facing aspects due to high temperature and low humidity (Lin and Sergio, 2009). Climatic parameters such as temperature, precipitation, and wind also play important role in forest fire risks.

In order to minimize the potential effects of fires on forest resources, forest fire risk zones should be determined and necessary precaution measures should be taken in these areas. Forest fire risk zones are defined as the areas where a fire is likely to start, and from where it can spread to other areas (Erten et al., 2004). A fire risk zone mapping is essential for an accurate assessment of forest fire problems (Jaiswal et al., 2002).

Forest fire risk maps can be generated based on spatial data layers representing various fire risk factors. Geographical Information System (GIS) techniques integrated with Multi-Criteria Decision Analysis (MCDA) method provides quick and effective solutions to such complex spatial problems (Jaiswal et al., 2002; Carmel et al., 2009). Analytical Hierarchy Process (AHP) is one of the widely used multi-criteria decision-support methods used in the field of forestry (Coulter et al., 2006; Gülci, 2014).

In this study, GIS-based AHP method was used to generate forest fire risk map. The method was implemented in Dursunbey Forest Enterprise Directorate (FED) which was categorized as one of the first-degree fire sensitive FEDs in Turkey. 


\section{MATERIAL AND METHODS}

\subsection{Study Area}

The study area was Yayla FEC within the borders of Dursunbey FED in Balıkesir, Turkey (Figure 1). The areal distribution of forest resources with respect to FECs located in the Dursunbey FED is indicated in Table 1. The elevation ranges from $360 \mathrm{~m}$ to $1625 \mathrm{~m}$ with the average of $859.27 \mathrm{~m}$. The ground slope varies between 0 and $208.89 \%$ with the average of $24.96 \%$. The dominant trees in the study area are Black Pine, Brutian Pine, Oak, and Beech.

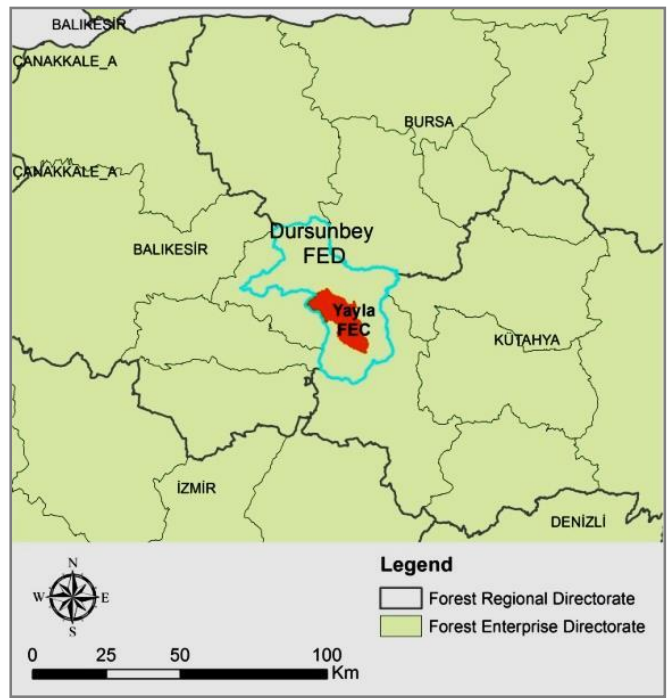

Figure 1. The study area map

\begin{tabular}{|l|c|c|c|}
\hline FECs & $\begin{array}{c}\text { High } \\
\text { Forest }\end{array}$ & $\begin{array}{c}\text { Degraded } \\
\text { Forest }\end{array}$ & $\begin{array}{c}\text { Total } \\
\text { Forest }\end{array}$ \\
\hline Candere & 9475.00 & 1420.20 & 10895.20 \\
Civana & 6745.60 & 3095.30 & 9840.90 \\
Çamlık & 6379.50 & 729.10 & 7108.60 \\
Durabeyler & 11283.80 & 3998.30 & 15282.10 \\
Dursunbey & 7116.10 & 9533.30 & 16649.40 \\
Gökçedağ & 8987.00 & 5593.90 & 14580.90 \\
Yayla & 8521.60 & 5157.10 & 13678.70 \\
Total & 58508.60 & 29527.20 & 88035.80 \\
\hline
\end{tabular}

Table 1.Forest resources in Dursunbey FED (ha) (URL-1)

\subsection{GIS Database}

The forest fire risk map was planned by using GIS-based AHP methods by considering risk factors including forest vegetation structures and topographic features. Climatic parameters were not included since they are uniform in the study area. To generate data layers for the risk factors, necessary digital data including forest management maps and topographic maps were obtained from Dursunbey FED. GIS applications were implemented by using ArcGIS 10.4.1.

\subsubsection{Forest Vegetation Structures}

Forest vegetation structures considered in this study were tree species, crown closure, and tree stage. The forest management map (1:25000) was used to generate land use map of Yayla FEC. Then, land use types (forest, agriculture, open areas, rocky areas, residential area, open areas-rocky areas, mines) were delineated (Figure 2). Finally, forest cover was produced by delineating the forested area which is border of the study site.

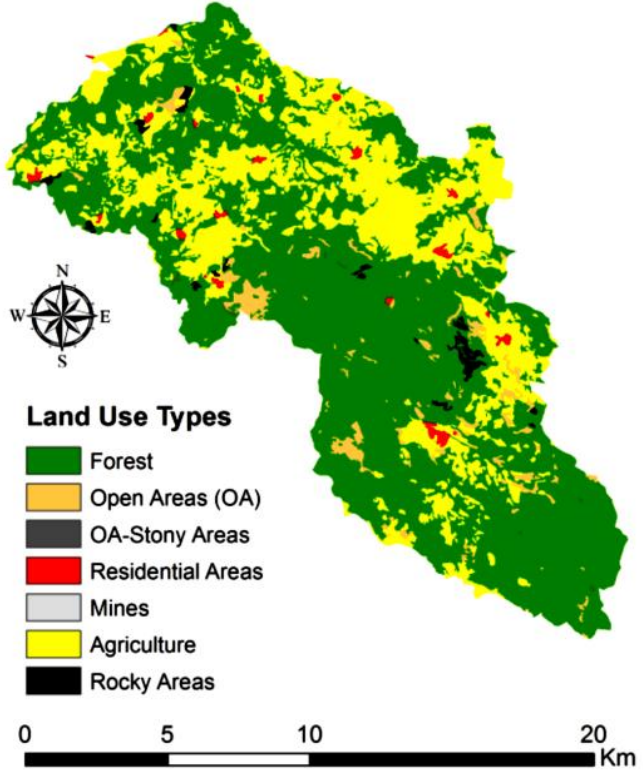

Figure 2. Land use map

The forest cover map was used to generate data layers for vegetation structures. There were total of 21 tree species or species compositions in the study area. Table 2 indicates tree species compositions and their stand type codes.

\begin{tabular}{|c|c|l|}
\hline No & $\begin{array}{c}\text { Stand Type } \\
\text { Codes }\end{array}$ & Tree Species Composition \\
\hline 1 & Çz & Brutian pine \\
2 & Çf-Çz & Stone pine-Brutian pine \\
3 & Çz-Çk & Brutian pine-Black pine \\
4 & Çk-Çz & Black pine -Brutian pine \\
5 & Çk & Black pine \\
6 & Ar & Juniper \\
7 & Çz-M & Brutian pine-Oak \\
8 & Çk-M & Black pine- Oak \\
9 & Ar-Dy & Juniper-Other deciduous trees \\
10 & Ar-M & Juniper- Oak \\
11 & M-Çz & Oak-Brutian pine \\
12 & M-Çk & Oak-Black pine \\
13 & Çk-Çs & Black pine-Yellow pine \\
14 & Çs-Çk & Yellow pine-Black pine \\
15 & M-Ar & Oak-Juniper \\
16 & Çk-Kn & Black pine-Beech \\
17 & Çk-Dy & Black pine- Other deciduous trees \\
18 & Çk-G & Black pine- Hornbeam \\
19 & Kn-Çk & Beech-Black pine \\
20 & M & Oak \\
21 & Dy & Other deciduous trees \\
\hline
\end{tabular}

Table 2. Tree species and species compositions in the study area

The crown closure is as a percent of total ground area covered by the crowns of trees or woody vegetation. The crown closure is divided into four classes including bare-land, sparse, moderate, and dense closures (Table 3 ). The fire risk increases as crown closure increases in the forested areas (Bilgili, 2003).

\begin{tabular}{|c|l|c|}
\hline No & $\begin{array}{l}\text { Crown } \\
\text { closures }\end{array}$ & $\begin{array}{c}\text { Total Covered } \\
\text { Ground Area }\end{array}$ \\
\hline 1 & Bare-land & $0-10$ \\
2 & Sparse & $11-40$ \\
3 & Moderate & $41-70$ \\
4 & Dense & $>70$ \\
\hline
\end{tabular}

Table 3. Areal distribution (\%) of crown closure classes 
The tree stages, also defined as stage of forest stand development, are generally categorized under seven classes (Table 4 ). The fire risk is very high at young generations, while it decreases from the mature to over mature stages (Sağlam et al., 2008).

\begin{tabular}{|c|l|}
\hline No & Tree Stages \\
\hline 1 & (a) newly planted-average $\mathrm{DBH}^{*}:<8 \mathrm{~cm}$ \\
2 & (a) regenerated and (b) young-average DBH: $<0-8$ and \\
& $8-19.9 \mathrm{~cm}$ \\
3 & (b) young-average DBH: $8-19.9 \mathrm{~cm}$ \\
4 & (b) young and (c) mature-average DBH: $8-19.9 \mathrm{~cm}$ and \\
& $20-35.9 \mathrm{~cm}$ \\
5 & (c) mature-average DBH: $20-35.9 \mathrm{~cm}$ \\
6 & (c) mature and (d) overmature-average DBH: $20-35.9$ \\
& and >36 cm \\
7 & (d) overmature-average DBH: $>36 \mathrm{~cm}$ \\
\hline
\end{tabular}

* DBH: Diameter of breast height taken as $1.3 \mathrm{~m}$ above the ground or above buttresses

Table 4. Tree stages

\subsubsection{Topographic Features}

Firstly, Digital Elevation Model (DEM) was generated using the contour lines (with $10 \mathrm{~m}$ intervals) on topographical maps (1:25000) (Figure 3). The slope map was produced based on the DEM $(10 \times 10 \mathrm{~m})$. Then, slope map was reclassified into five classes (Table 5). Finally, the aspect map was produced based on the same DEM.

\begin{tabular}{|c|c|c|}
\hline No & Slope Classes & Slope Values \\
\hline 1 & Gentle & $0-5$ \\
2 & Low & $5-15$ \\
3 & Medium & $15-25$ \\
4 & High & $25-35$ \\
5 & Steep & $>35$ \\
\hline
\end{tabular}

Table 5. Ground slope (\%) classes

\subsection{AHP Method}

The fire risk map was developed by GIS-based Analytic Hierarchy Process (AHP) method. Myers and Alpert (1968) first described AHP and then it was modelled by Saaty (1977). The AHP method evaluates a set of evaluation criteria and search for the optimal solution among a set of alternative options. In the solution process of AHP, the study area was classified into four forest fire risk classes (options): low, moderate, high, and extreme. The main criteria were tree species, crown closure, tree stage, slope, and aspect. Decision maker's pairwise comparisons were used to generate a weight for each criterion. The relative importance between two criteria was measured based on a numerical scale from 1 to 9 (Table 6).

\begin{tabular}{|c|c|}
\hline $\begin{array}{l}\text { Importance } \\
\text { Scale }\end{array}$ & Definitions \\
\hline 1 & Equal importance \\
\hline 3 & $\begin{array}{l}\text { Weak importance of one over } \\
\text { another }\end{array}$ \\
\hline 5 & Essential or strong importance \\
\hline 7 & Demonstrated importance \\
\hline 9 & Absolute importance \\
\hline $2,4,6,8$ & $\begin{array}{l}\text { Intermediate values between the } \\
\text { two adjacent judgments }\end{array}$ \\
\hline
\end{tabular}

Table 6. The relative importance values
Firstly, the relative importance values among sub-criteria were evaluated regarding with potential fires risk. The higher score was given when the criterion was more important. The normalized pairwise comparison matrix was used to compute the weighted averages of the sub-criteria. Then, "Reclassify" tool under "Spatial Analyst" extension of ArcGIS 10.2 was used to assign weighted average values to the corresponding criteria.

A pairwise comparison matrix $A$ was generated to compute the weights for the different criteria (or sub-criteria). Each entry $\left(a_{j i}=\right.$ $1 / a_{i j}$ ) of the matrix $A$ represents the importance of the $j$ th criterion relative to the $i$ th criterion. If $a_{j i}>1$, the $j$ th criterion is more important than the $i$ th criterion.

In the next step, normalized pairwise comparison matrix was generated. The column vector of $B$ was produced by using fallowing formula (Gülci, 2014):

$$
b_{j i}=\frac{a_{j i}}{\sum_{j=1}^{n} a_{j i}}
$$

where $b_{j i}$ is each entry at the column and $n$ is the number of criteria. Then, weighted averages of the criteria $\left(w_{j}\right)$ were computed by averaging the entries on each row using formula below (Gülci, 2014):

$$
w_{j}=\frac{\sum_{i=1}^{n} c_{j i}}{n}
$$

The ratio of Consistency Index $(C I)$ and Random Index $(R I)$ were also computed to check the consistency of the evaluations made for the pairwise comparison matrices. The small value of this ratio $(<0.1)$ reveals that consistent results can be achieved from the AHP method.

After consistency analysis, "Spatial Analyst" extension of ArcGIS 10.4.1 was used to assign weighted average values $\left(w_{j}\right)$ to the corresponding criteria. Then, "extAhp 2.0" plug-in was used to combine the weighted averages of the criteria and determine the AHP scores. Finally, the forest cover in the study area was categorized according to fire risk classes.

\section{RESULTS AND DISCUSSION}

\subsection{GIS Data Layers}

\subsubsection{Forest Vegetation Structures}

The areal distribution of land use types is indicated in Table 7. It was found that most of the study area was covered by forests $(65.26 \%)$, followed by agriculture $(29.54 \%)$ and open areas $(3.46 \%)$. Other land use types were insignificant. In terms of tree species, the most common species was Black pine $(45.55 \%)$ followed by Oaks (12\%). Figure 3 indicates the map of tree species represented by their associated stand type codes.

\begin{tabular}{|l|c|}
\hline Land Use Types & Area \\
\hline Forest & 65.26 \\
Agriculture & 29.54 \\
Open Areas (OA) & 3.46 \\
Rocky Areas & 0.85 \\
Residential Areas & 0.81 \\
OA-Stony Areas & 0.07 \\
Mines & 0.01 \\
\hline
\end{tabular}

Table 7. Areal distribution (\%) of the land use types 


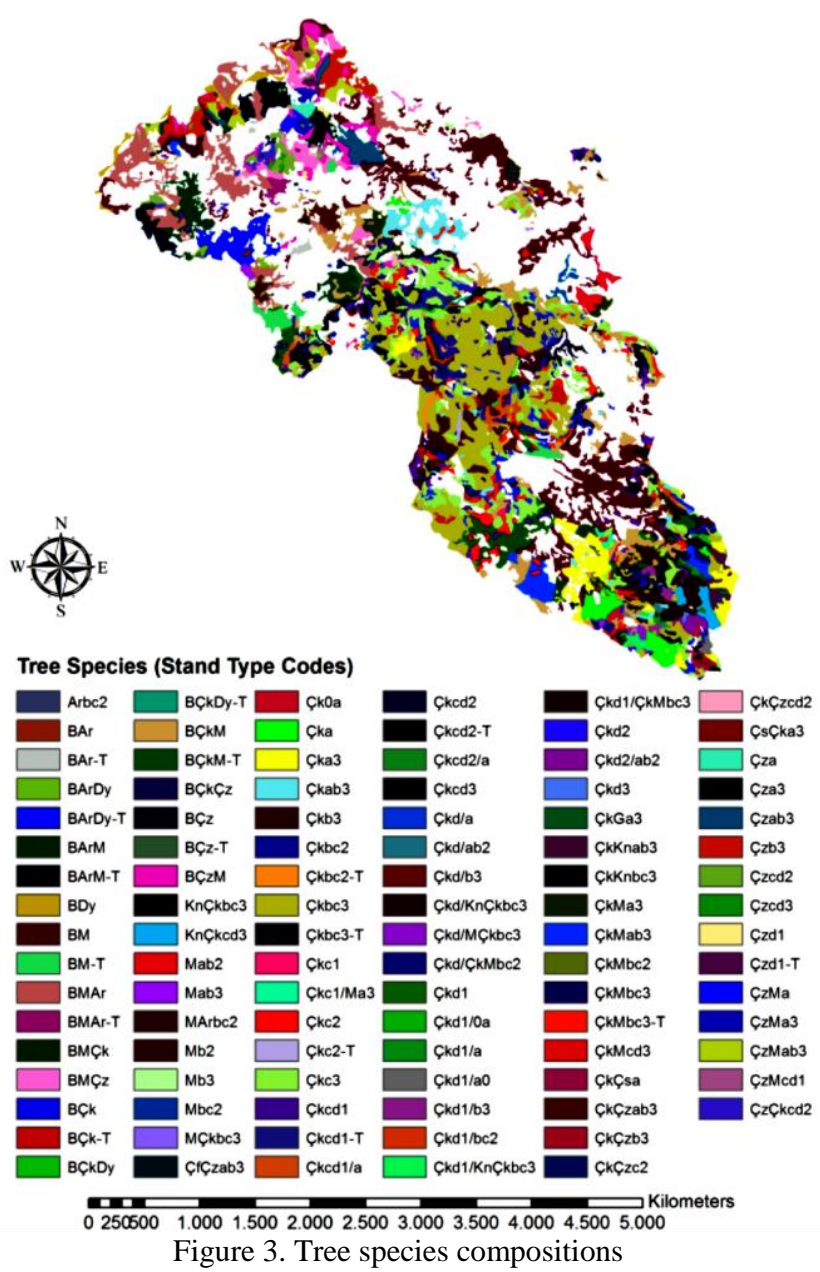

The crown closure map is shown in Figure 4. The results indicated that crown closure was dense in $43 \%$ of the study area, while it was bare-land in $41 \%$ of the area. The percentages of the sparse and moderate closure were $6 \%$ and $10 \%$, respectively.

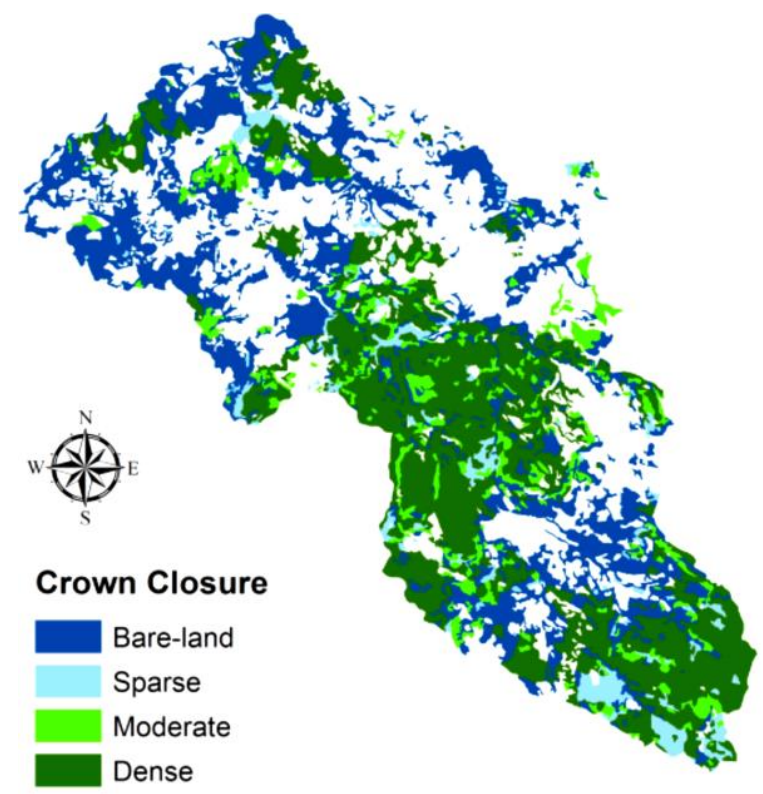

02505001.0001 .5002 .0002 .5003 .0003 .5004 .0004 .5005 .000

Figure 4. The crown closure map

The results indicated that half of the study area was covered by mature tree stages (DBH: $20-35.9 \mathrm{~cm}$ ). The tree stages at young and mature combination covered the second largest area (19\%). It was reported that the fire risk is very high at young generations (Sağlam et al., 2008).

\subsubsection{Topographic Features}

The ground slope map indicated that $31.76 \%$ of the study area was on very steep slope class, while $22.19 \%$ was on medium slope class (Figure 5, Table 8). Previous studies marked that fire risk is relatively higher on steep terrains (Jaiswal et al., 2002).

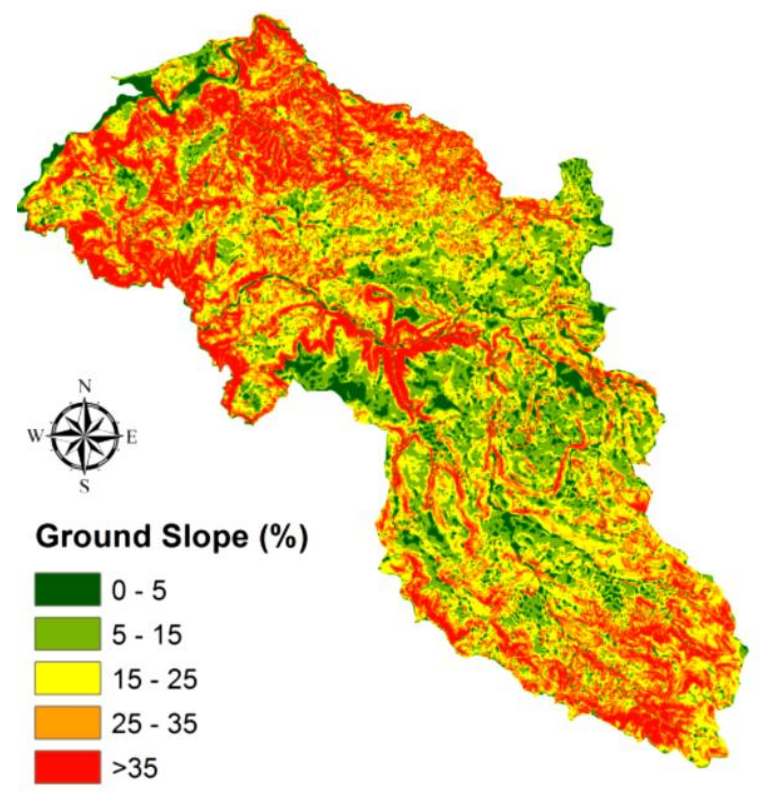

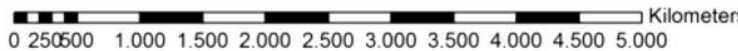

Figure 5. Ground slope map

\begin{tabular}{|l|c|}
\hline Slope Classes & Area \\
\hline Gentle & 8.00 \\
Low & 16.35 \\
Medium & 22.19 \\
High & 21.70 \\
Steep & 31.76 \\
\hline
\end{tabular}

The aspect map of the study area was also generated. The results indicated that $20.37 \%$ of the study area was located on north aspect, followed by north-east aspect (14.80\%) (Table 9, Figure 6). The proportion of south-facing aspects was $28.12 \%$, which has higher fire risk due to high temperature and low humidity (Lin and Sergio, 2009).

\begin{tabular}{|c|c|}
\hline Aspects & Area \\
\hline $\mathrm{N}$ & 20.37 \\
$\mathrm{NE}$ & 14.80 \\
$\mathrm{E}$ & 9.62 \\
$\mathrm{SE}$ & 7.10 \\
$\mathrm{~S}$ & 8.11 \\
$\mathrm{SW}$ & 12.91 \\
$\mathrm{~W}$ & 13.22 \\
$\mathrm{NW}$ & 13.86 \\
\hline
\end{tabular}

Table 9. Areal distribution (\%) of the aspects 


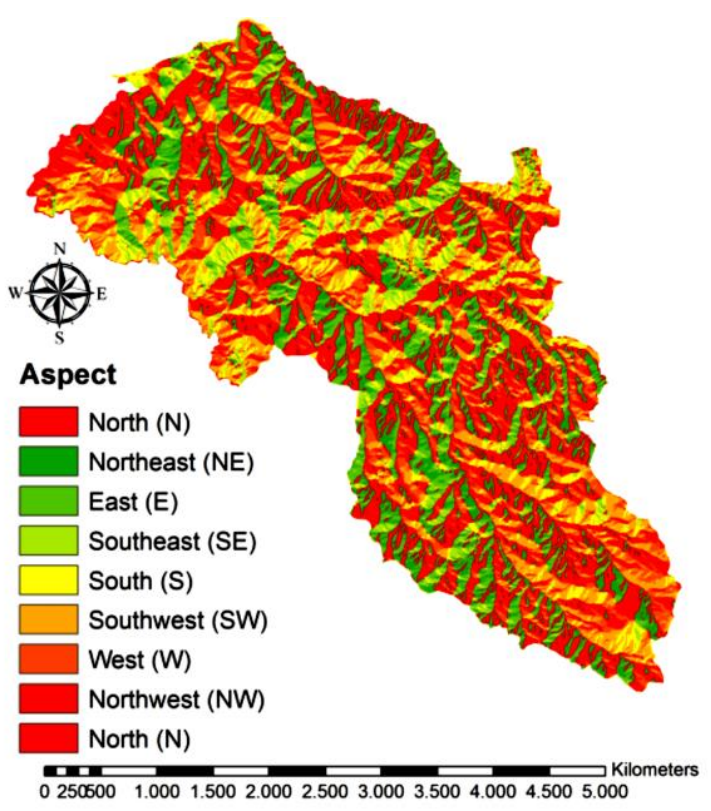

Figure 6. Aspect map

\subsection{AHP Results}

A pairwise comparison matrix was generated to compute the weighted values for the criteria and their sub-criteria. The weighted values of tree species criteria (and sub-criteria) were indicated in Table 10. The pure coniferous forest followed by mixed coniferous forest had the highest weighted values. Oak tree and other deciduous trees had the lowest weighted values (Gazzard, 2012).

\begin{tabular}{|c|l|c|}
\hline No & Tree Species Composition & Values \\
\hline 1 & Brutian pine & 0.084 \\
2 & Stone pine-Brutian pine & 0.084 \\
3 & Brutian pine-Black pine & 0.075 \\
4 & Black pine -Brutian pine & 0.075 \\
5 & Black pine & 0.065 \\
6 & Juniper & 0.065 \\
7 & Brutian pine-Oak & 0.056 \\
8 & Black pine- Oak & 0.047 \\
9 & Juniper-Other deciduous trees & 0.047 \\
10 & Juniper- Oak & 0.047 \\
11 & Oak-Brutian pine & 0.047 \\
12 & Oak-Black pine & 0.037 \\
13 & Black pine-Yellow pine & 0.037 \\
14 & Yellow pine-Black pine & 0.037 \\
15 & Oak-Juniper & 0.037 \\
16 & Black pine-Beech & 0.037 \\
17 & Black pine- Other deciduous trees & 0.028 \\
18 & Black pine- Hornbeam & 0.028 \\
19 & Beech-Black pine & 0.028 \\
20 & Oak & 0.019 \\
21 & Other deciduous trees & 0.019 \\
\hline
\end{tabular}

Table 10. The weighted values of tree species

Table 11 indicates the weighted values of crown closure criteria (and sub-criteria). It was found that forests with dense crown closure had the highest weighted values, followed by moderate crown closure (Bilgili, 2003). The weighted values of tree stage criteria (and sub-criteria) were indicated in Table 12. The regenerated and young stages had the highest weighted values, while overmature stage had the lowest values.

\begin{tabular}{|c|l|c|}
\hline No & Crown closures & Values \\
\hline 1 & Bare-land & 0.09 \\
2 & Sparse & 0.18 \\
3 & Moderate & 0.32 \\
4 & Dense & 0.41 \\
\hline
\end{tabular}

Table 11. The weighted values of crown closure

\begin{tabular}{|l|c|}
\hline Tree Stages & Values \\
\hline (a) newly planted-average DBH*: <8 cm & 0.08 \\
(a) regenerated and (b) young-average DBH: < 0- & 0.24 \\
8 and 8-19.9 cm & \\
(b) young-average DBH: 8-19.9 cm & 0.24 \\
(b) young and (c) mature-average DBH: 8-19.9 & 0.18 \\
cm and 20-35.9 cm & \\
(c) mature-average DBH: $20-35.9 \mathrm{~cm}$ & 0.16 \\
(c) mature and (d) overmature-average DBH: 20- & 0.08 \\
35.9 and >36 cm & 0.03 \\
(d) overmature-average DBH: $>36 \mathrm{~cm}$ & \\
\hline
\end{tabular}

Table 12. The weighted values of tree stages

The weighted values of ground slope criteria (and sub-criteria) were indicated in Table 13. The steep slope and high slope areas had the highest weighted values. For the aspect criterion, south and southwest aspects had the highest weighted values, while north aspect had the lowest (Table 14).

\begin{tabular}{|c|c|}
\hline Slope Classes & Values \\
\hline Gentle & 0.04 \\
Low & 0.12 \\
Medium & 0.20 \\
High & 0.28 \\
Steep & 0.36 \\
\hline
\end{tabular}

Table 13. The weighted values of slopes

\begin{tabular}{|c|l|}
\hline Aspects & Values \\
\hline $\mathrm{N}$ & 0.05 \\
$\mathrm{NE}$ & 0.09 \\
$\mathrm{E}$ & 0.09 \\
$\mathrm{SE}$ & 0.14 \\
$\mathrm{~S}$ & 0.20 \\
$\mathrm{SW}$ & 0.20 \\
$\mathrm{~W}$ & 0.09 \\
$\mathrm{NW}$ & 0.09 \\
$\mathrm{~N}$ & 0.05 \\
\hline
\end{tabular}

Table 14. The weighted values of the aspects

The weighted averages of the criteria were combined and foret fire risk map was generated by using "extAhp 2.0" tool in ArcGIS 10.4.1. Table 15 shows the weighted average values of criteria assigned to forest fire risk map. The result indicated that the most effective criterion was tree species, followed by tree stages. Crown closure and slope criteria had the similar effect of fire risk, while aspect had the least effective criterion on forest fire risk.

\begin{tabular}{|c|c|}
\hline Criteria & Values \\
\hline Tree species & 0.28 \\
Crown Closure & 0.19 \\
Tree Stage & 0.22 \\
Slope & 0.19 \\
Aspect & 0.13 \\
\hline
\end{tabular}

Table 15 . The weighted values of criteria

Figure 7 indicates the distribution of forest fire risk map with respect to all the criteria. Based on the GIS-based AHP method, 
about $32 \%$ and $26 \%$ of the forests in the study area were within the moderate and high fire risk zones, respectively (Table 16). About $24 \%$ of the forests were classified as extreme fire risk areas.

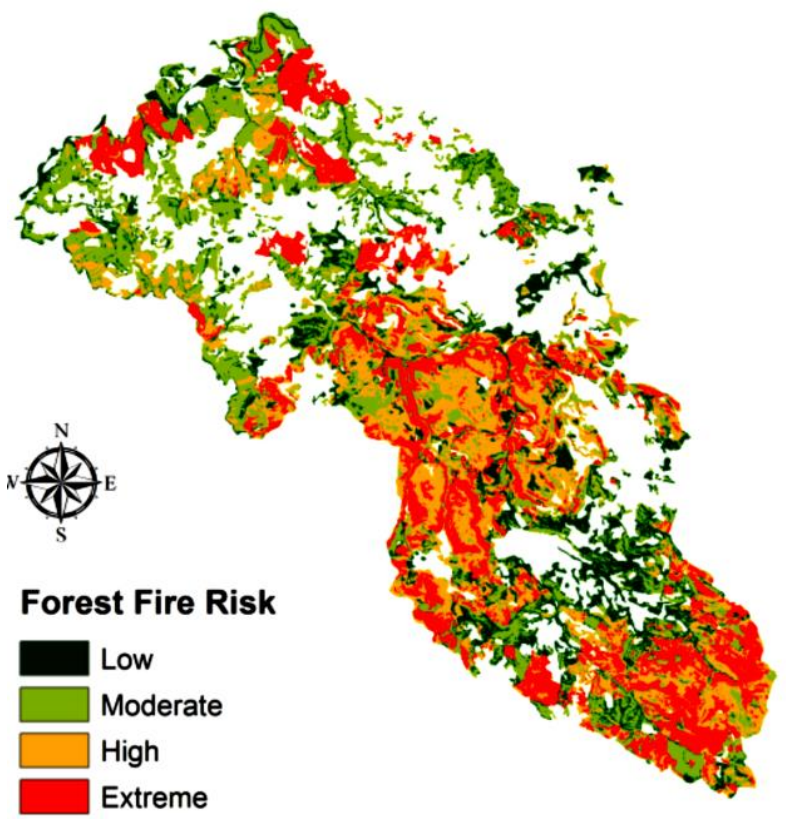

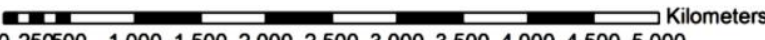
02506001.0001 .5002 .0002 .5003 .0003 .5004 .0004 .5005 .000 Figure 7. Forest fire risk map

\begin{tabular}{|l|c|}
\hline Fire Risk & Area \\
\hline Low & 17.97 \\
Moderate & 32.41 \\
High & 25.81 \\
Extreme & 23.81 \\
\hline
\end{tabular}

Table 16. The areal distribution (\%) of fire risk levels

\section{CONCLUSIONS}

Forest fires may cause devastating impacts on forest resources, and important economic losses and even threaten human lives. It is critical to determine the forested areas with fire risks and thereby taking necessary precaution measures to minimize the damages on forest resources. In this study, GIS-based MultiCriteria Decision Analysis (MCDA) using AHP method was used to generate forest fire risk map. The method was implemented in Dursunbey Forest Enterprise Directorate which is classified as first degree fire sensitive area in Turkey. In the solution process, forest vegetation structures (i.e. tree species, crown closure, tree stage) and topographic features (i.e. slope and aspect) were considered as main criteria. Quick and effective prediction of forest fire risk will assist decision makers take necessary action and minimize fire damage on the forest resources. Possible future studies may include considering additional fire risk factors such as distance to road network, distance to residential areas, and climatic parameters in developing fire risk maps.

\section{REFERENCES}

Akay, A.E., Erdas, O., Kanat, M., Tutus, A., 2007. Post-Fire Salvage Logging for Fire-Killed Brutian Pine (Pinus brutia) Trees. Journal of Applied Sciences 7(3), pp. 402-406.
Akay, A.E., Wing, M.G., Zengin, M., Köse, O., 2017. Determination of fire-access zones along road networks in fire sensitive forests. J. For. Res., 28(3), pp. 557-564.

Bilgili, E., 2003. Stand Development and Fire Behavior. Forest Ecol. Manag. 179, pp. 333-339.

Bilici, E., 2009. A Study on the Integration of Firebreaks and Fireline with Forest Roads Networks and It's Planning and Construction (A Case Study of Gallipoly National Park) Istanbul University. Faculty of Forestry Journal Series: A 59(2), pp. 86102.

Carmel, Y., Paz, S., Jahashan, F., Shoshany, M., 2009. Assessing fire risk using Monte Carlo simulations of fire spread. Forest Ecol. Manag. 257(1), pp. 370-377.

Coulter, E.D., Coakley, J., Sessions, J., 2006. The Analytic Hierarchy Process: A tutorial for Use in Prioritizing Forest Road Investments to Minimize Environmental Effects. International Journal of Forest Engineering. 17(2), pp. 51-69.

Demir, M., Kucukosmanoglu, A., Hasdemir, M., Ozturk, T., Acar, H.H., 2009. Assessment of forest roads and firebreaks in Turkey. African Journal of Biotechnology, 8(18), pp. 4553-4561.

Erten, E., Kurgun, V., Musaoglu, N., 2004. Forest Fire Risk Zone Mapping from Satellite Imagery and GIS a Case Study. XXth ISPRS Congress, Youth Forum, Editor(s): Orhan Altan, July 1223, Istanbul, Turkey. pp. 33-39.

Gao, X., Fei, X., Xie, H., 2011. Forest fire risk zone evaluation based on high spatial resolution RS image in Liangyungang Huaguo Mountain Scenic Spot. IEEE International Conference on Spatial Data Mining and Geographical Knowledge Services. Fuzhou, China.

Gazzard, R., 2012. Risk Management Control Measure: Toolkit for Practitioners and Advisors. UK Vegetation Fire Risk Management. $24 \mathrm{p}$.

Guido, R., Van derr Werf, J.T., Randerson, G., James Collatz, L., Giglio, P.S., Kasibhatl,a A.F., 2004. Continental-scale partitioning of fire emissions during the 1997-2001 El Nino/La Nina period. Science, 303: pp. 73-76.

Gülci, N. 2014. Researches on precision forestry in forest planning. Ph.D. thesis, KSU, Kahramanmaraş. 264 p.

Jaiswal, R.K., Mukherjee, S., Raju, D.K., Saxena, R., 2002. Forest fire risk zone mapping from satellite imagery and GIS. International Journal of Applied Earth Observation and Geoinformation, 4 (2002), pp.1-10.

Lin, J., Sergio, R., 2009. A derivation of the statistical characteristics of forest fires. Ecological Modelling 220: pp. 898903.

Myers, J.H., Alpert, M.I., 1968. Determinant Buying Attitudes: Meaning and Measurement, Journal of Marketing, 32: pp. 13-20.

Saaty, T.L., 1977. A scaling method for priorities in hierarchical structures. J Math Psychol. 15: pp. 234-281.

Sağlam, B., Bilgili, E., Durmaz, B.D., Küçük, Ö., Kadığulları, A.İ., Küçük, Ö., 2008. Spatio-temporal analysis of forest fire risk and danger using LANDSAT imagery, Sensors, 8, pp. 39703987.

URL-1. GDF, Balıkesir Regional Directorate of Forestry, http://balikesirobm.ogm.gov.tr/Sayfalar/Kurulusumuz/isletmeMudurluklerimiz/Dursunbey-Ois.aspx (Last visited: 1/08/2017) 